emission CT will be negative owing to lack of uptake of tracer in the lesion. In terms of detection (sensitivity) this remains a drawback of emission CT. If these patients are scanned during the two weeks when tracer concentration peaks within the lesion emission and transmission CT achieve the same detection rate, which explains the high percentage of concordant results obtained in the patients with vascular disease. Transmission CT, however, yields a few false-negative results in isodense vascular disease.

In this series the rate of false-positive results obtained with emission CT was $0 \%$ and the rate of false-negative results was extremely low $(2.4 \%$ in detecting primary or secondary intracranial neoplasms).

Emission CT is becoming more available. Within the past year at least seven centres in the UK alone emerged with the technical infrastructure required to record computed emission tomograms. We do not doubt that further work will progressively show its clinical potential.

In terms of patient throughput, total scan time with an emission brain scanner averaged 30 minutes. Other systems exist whereby data collection may be completed in 15-20 minutes. We hope to cut our total scanning time by half to $10-15$ minutes per patient. This may be achieved without appreciable loss in image detail. In terms of radiation exposure, a standard $99 \mathrm{~m}$ Tc brain scan delivers a dose in the order of $100 \mathrm{mrad}$; the dose to a slice in the brain from transmission scans varies from 1.5 to $2 \mathrm{rad}$.
With every new technique the question of costs arises. Purchase costs for available emission CT equipment are known, but cost-effectiveness is difficult to assess. A camera computer system designed to perform emission CT may cost from $£ 10000$ to $£ 20000$ over and above the expenditure necessary to buy the camera computer system (of the order of $£ 80000)$. The cost of our instruments falls within this range.

Requests for reprints should be sent to PJE.

\section{References}

${ }^{1}$ Kan MK, Hopkins GB. Measurement of liver volume by emission computed tomography. $\mathcal{F}$ Nucl Med $1979 ; 20: 514-20$.

${ }^{2}$ Vogel RA, Kirch D, LeFree M, Steele P. A new method of multiplanar emission tomography using a seven pinhole collimator and an Anger scintillation camera. F Nucl Med 1978;19:648-54.

${ }^{3}$ Ell PJ, Jarritt PH, Langford R, Pearce PC, Deacon JM. Is there a future for single photon emission tomography? ROEFO 1979;130:499-507.

${ }^{4}$ Ell PJ, Jarritt PH, Deacon JM, Brown NJG. Emission computerized tomography : a new diagnostic imaging technique. Lancet 1978;ii :608-10.

${ }^{5}$ Jarritt PH, Ell PJ, Myers MJ, Brown NJG, Deacon JM. A new transversesection brain imager for single-gamma emitters. F Nucl Med 1979;20: 319-27.

${ }^{6}$ Ducassou D, Brendel A, Brothier JP, Lacroix F. Single photon emission computed tomography: clinical value in brain imaging. Eur $\mathcal{f}$ Nucl Med $1979 ; 4: 142$ (abstr).

(Accepted 20 November 1979)

\title{
Computed tomography for determining liver iron content in primary haemochromatosis
}

\author{
R W G CHAPMAN, G WILLIAMS，G BYDDER， R DICK， SHEILA SHERLOCK， L KREEL
}

\section{Summary and conclusions}

Dual-energy computed tomography (CT) was used to estimate hepatic iron concentration in eight patients with primary haemochromatosis with varying degrees of iron overload. The values corresponded closely with those derived from chemical analysis of liver tissue obtained by biopsy (correlation coefficient 0.993 ).

Dual-energy CT therefore seems to provide an accurate and non-invasive alternative to liver biopsy as a means of measuring liver iron concentration in patients with primary haemochromatosis and possibly other iron overload states.

Academic Department of Medicine, Royal Free Hospital, London R W G CHAPMAN, BSC, MRCP, Watson Smith research fellow of Royal College of Physicians of London

SHEILA SHERLOCK, MD, FRCP, professor of medicine

Division of Radiology, Clinical Research Centre and Northwick Park Hospital, Harrow

G WILLIAMS, DIC, MINSTP, research fellow

G BYDDER, FRACP, research fellow

L KREEL, MD, FRCR, head of division

Department of Radiology, Royal Free Hospital, London

R DICK, MRACR, FRCR, consultant radiologist

\section{Introduction}

Physicochemical measurement of iron concentration in tissue obtained at liver biopsy is the most reliable index of total body iron stores in primary haemochromatosis. ${ }^{12}$ The presence of increased hepatic iron in this disease may be suggested by computed tomography (CT), ${ }^{3}$ but the use of CT for estimating the amount of hepatic iron has not been described in primary haemochromatosis.

In this study we compared estimates of hepatic iron concentration obtained with CT using a dual-energy technique with results obtained by chemical analysis of liver biopsy material.

\section{Methods}

Seven men and one woman with primary haemochromatosis were studied. The diagnosis was established clinically and by a raised liver iron content in the absence of another cause for siderosis. Two patients had a family history of the disease. All patients had had a liver biopsy within six weeks of CT scanning and no patient had been venesected between the time of CT scanning and biopsy.

\section{IRON STUDIES}

Serum iron concentration, total iron binding capacity, and percentage iron saturation of iron binding capacity were measured using standard laboratory methods. Serum ferritin was measured by radioimmunoassay. ${ }^{4}$ 
Percutaneous liver biopsies were performed using Menghini needles. The iron content was graded histologically according to the criteria of Scheuer et al. ${ }^{5}$ Iron was measured chemically in the biopsy samples by the method of Barry and Sherlock. ${ }^{6}$

\section{CT STUDIES}

An EMI CT5005 scanner was used with experimental V05 new convolution software. By using a special phantom CT numbers were generally reproducible to \pm 0.2 EMI units at $140 \mathrm{kV}$ and \pm 0.3 EMI units at $110 \mathrm{kV}$. Consecutive scans gave much better reproducibility to $0 \pm 0 \cdot 1$ units at both $\mathrm{kV}$.

Patients were scanned with bolus bags incorporating water and air controls. Four 20-second clockwise scans of the liver were obtained in the same position for each patient at $140 \mathrm{kV}$ and $110 \mathrm{kV}$ for $400-\mathrm{mm}$ and $320-\mathrm{mm}$ wedge fields.

A venous blood sample was taken and placed in the centre of a calibration phantom, which was scanned at $140 \mathrm{kV}$ and $110 \mathrm{kV}$. CT attenuation values for liver, aortic blood, and venous blood samples were obtained. These values were air-scale corrected, and the difference in liver and aortic blood attenuation values with the same wedge at different energies-the dual-energy differentials (DED)-were determined. The blood value was used as a control.

The theoretical DED for liver containing iron at different effective energies was calculated from mass fraction lists ${ }^{7} 8$ by varying the iron mass fraction while adjusting the mass fraction of all other elements to keep the total mass fraction at unity. The listed liver iron mass fraction corresponds to a value of $0.75 \mathrm{mg} / \mathrm{g}$ dry tissue.

Comparison of the experimental and theoretical DEDs enabled the liver iron content to be estimated.

\section{Results}

The results of the iron and CT studies are shown in the table. The iron content measured chemically varied from normal in a treated patient to over 30 times the upper limit of normal in a patient who had not been venesected. The chemical liver iron values correlated

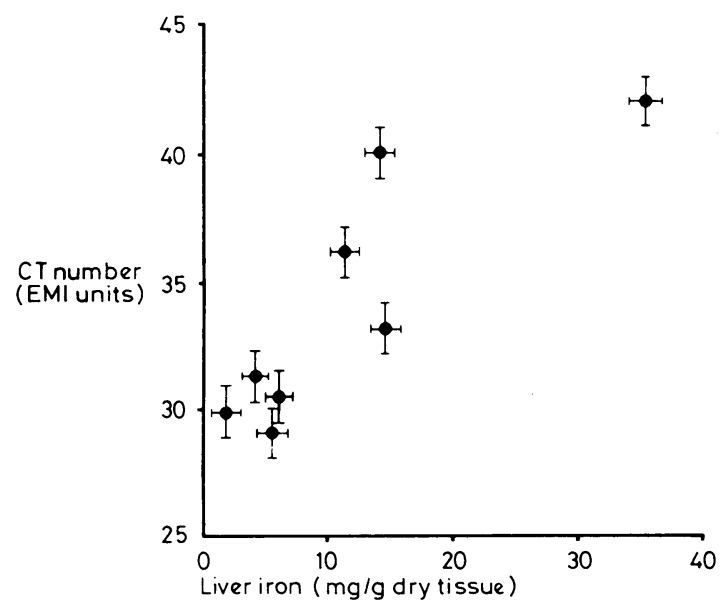

Liver attenuation values at $140 \mathrm{kV}$ with $320-\mathrm{mm}$ wedge plotted against chemical iron concentration. closely with the CT estimate of liver iron (correlation coefficient = 0.993; p < 0.001).

Liver attenuation values at $140 \mathrm{kV}$ using the $320-\mathrm{mm}$ wedge pair are plotted against chemical iron concentration in the figure. The correlation between single-energy attenuation values and chemical liver iron values was less exact (correlation coefficient $=0.8599$; $\mathrm{p}<0.01)$.

Serum ferritin concentrations did not correlate as closely as C.T values with the chemical liver iron concentrations $(r=0.7206 ; p<0.05)$.

\section{Discussion}

Liver biopsy is accepted as the most reliable technique for estimating iron stores, but it carries some morbidity and mortality. ${ }^{9}$ The close correlation between CT estimates of liver iron and the chemical iron results suggests that CT may provide an accurate alternative. The technique might also be of value in screening relatives of patients with primary haemochromatosis and other diseases associated with iron overload.

In this study CT provided a closer correlation with the chemical liver iron estimation than the serum ferritin concentration. Previous studies ${ }^{12}$ have shown that the serum ferritin concentration may be normal in precirrhotic haemochromatosis and may be increased by alcohol abuse ${ }^{10}$ and hepatic necrosis, ${ }^{11}$ which should not affect the CT estimation.

This technique, which needs a scanner able to scan at varying kilovoltages and with three scan field sizes (in particular at 110 and $140 \mathrm{kV}$ and 32 and $40 \mathrm{~cm}$ ring size), requires particular care to avoid sources of error. These include drift of the $\mathrm{kV}$ setting $( \pm 0.2 \mathrm{kV})$, excessive photomultiplier gain, the partial volume effect, and artefacts. The use of blood as an in-vitro and in-vivo control provides a correction for spectral errors due to variation in patient size and anatomy.

A variation of $10 \mathrm{EMI}$ units in the attenuation value of liver may be produced by variation in the physical density of liver within the normal range of 1.05 to $1.07 \mathrm{~g} / \mathrm{ml}$, or by a change in iron content of about $20 \mathrm{mg} / \mathrm{g}$ dry tissue at a constant physical density. The strong dependence of the dual-energy differential on the concentration of elements of high atomic number, such as iron, permits a separation of these two effects. Using a single-energy technique Houang $e t$ al $^{12}$ found a linear relationship between CT number and iron concentration in thalassaemia major. In this study, with lower liver iron concentrations, singleenergy CT values did not give such a close correlation. In addition, an abnormal DED, indicating a raised iron concentration, may be found even when liver attenuation values are within the normal range (variously quoted as 23.5-43.6 EMI units ${ }^{13}$ and $31 \pm 7$ units $\left.^{14}\right)$.

This technique appears to provide an accurate non-invasive measure of liver iron concentration which may have clinical application in primary haemochromatosis and other iron overload states.

\section{References}

1 Wands JR, Rowe JA, Mezey SE, et al. Normal serum ferritin concentrations in precirrhotic haemochromatosis. New Engl f Med 1976;294: 302-5.

Iron studies and $C T$ results

\begin{tabular}{|c|c|c|c|c|c|c|c|}
\hline Case No & $\begin{array}{c}\text { Age and } \\
\text { sex }\end{array}$ & $\begin{array}{c}\text { Ferritin } \\
(\mu \mathrm{g} / \mathbf{l})\end{array}$ & $\begin{array}{c}\text { Grade of } \\
\text { histological } \\
\text { liver iron }\end{array}$ & Biopsy histology & $\begin{array}{c}\text { Chemical liver iron } \\
(\mathrm{mg} / \mathrm{g})\end{array}$ & $\begin{array}{l}\text { Measured CT number } \\
\text { (liver dual energy } \\
\text { differential) }\end{array}$ & $\begin{array}{c}\text { Estimated } \\
\text { CT liver } \\
\text { iron }(\mathrm{mgm} / \mathrm{g})\end{array}$ \\
\hline $\begin{array}{l}1 \\
2 \\
3 \\
4 \\
5 \\
6 \\
7 \\
8\end{array}$ & $\begin{array}{l}64 M \\
54 M \\
42 M \\
58 M \\
52 M \\
62 M \\
58 M \\
69 \mathrm{~F}\end{array}$ & $\begin{array}{r}480 \\
2300 \\
1600 \\
120 \\
10 \\
800 \\
2600 \\
1975\end{array}$ & $\begin{array}{c}3-4 \\
4 \\
4 \\
2-3 \\
0 \\
2-3 \\
4 \\
2-3\end{array}$ & $\begin{array}{l}\text { Cirrhosis } \\
\text { No"cirrhosis } \\
\text { " " ", } \\
\text { C̈̈rrhosis" } \\
\text { ", }\end{array}$ & $\begin{array}{r}11 \cdot 00 \\
14 \cdot 28 \\
13 \cdot 80 \\
4 \cdot 16 \\
1 \cdot 76 \\
5 \cdot 40 \\
35 \cdot 71 \\
5 \cdot 75\end{array}$ & $\begin{array}{l}2 \cdot 0 \\
2 \cdot 8 \\
2 \cdot 7 \\
0 \cdot 9 \\
0 \cdot 6 \\
1 \cdot 0 \\
5 \cdot 7 \\
1 \cdot 5\end{array}$ & $\begin{array}{r}10.59 \\
15.75 \\
14.84 \\
3.90 \\
2.08 \\
4.51 \\
33.08 \\
7.55\end{array}$ \\
\hline Normal va & s... & $\begin{array}{l}M<360 \\
F<180\end{array}$ & $<2$ & & $<1.40$ & & 0.75 \\
\hline
\end{tabular}


${ }^{2}$ Batey RG, Hussein S, Sherlock S, Hoffbrand AV. The role of serum ferritin in the management of idiopathic haemochromatosis. Scan $\mathcal{F}$ Gastroenterol 1978;13:953-7.

${ }^{3}$ Fawcitt RA, Forbes W St C, Isherwood I, et al. Computed tomographic scanning in liver disease. Clin Radiol 1978;29:251-4.

${ }^{4}$ Addison GM, Beamish MR, Hales $\mathrm{CN}$, et al. An immunoradiometric assay for ferritin in the serum of normal subjects and patients with iron deficiency and iron overload. F Clin Pathol 1972;25:326-9.

5 Scheuer PJ, Williams R, Muir AR. Hepatic pathology in relatives of patients with haemochromatosis. $\mathcal{F}$ Pathol Bacteriol 1962;84:53-64.

${ }^{6}$ Barry M, Sherlock S. Measurement of liver-iron concentration in needlebiopsy specimens. Lancet 1971 ; i:100-3.

7 ICRP. Reference man: anatomical, physiological and metabolic characteristics. Report 25. Oxford: Pergamon Press, 1975.

8 Veigele WJ. Photon cross-sections from $0 \cdot 1 \mathrm{keV}$ to $1 \mathrm{meV}$ for elements $\mathrm{Z}=1$ to $\mathrm{Z}=94$. Atomic Data Tables $1973 ; 5(1): 51-111$.

${ }^{9}$ Sherlock S. Diseases of the liver and biliary system. Oxford: Blackwell Scientific Publications, $1975: 49-50$.
${ }^{10}$ Halliday JW, Russo AM, Cowlishaw JL, Powell LW. Serum ferritin in diagnosis of haemochromatosis. Lancet 1977 ;ii:621-4.

11 Prieto J, Barry M, Sherlock S. Serum ferritin in patients with iron overload and with acute and chronic liver diseases. Gastroenterology 1975;68: 525-33.

${ }^{12}$ Houang MTW, Arozena X, Skalicka A, Huehns ER, Shaw DG. Correlation between computed tomographic values and liver iron content in thalassaemia major with iron overload. Lancet 1979;i:1322-3.

${ }^{13}$ Mills SR, Doppman JL, Nienhuis AW. Computed tomography in the diagnosis of disorders of excessive iron storage of the liver. $\mathcal{F}$ Comp Assist Tomogr 1977;1(1):101-4.

14 Mategrano VC, Petasnick J, Clark J, Chung Bin A, Weinstein R. Attenuation values in computed tomography of the abdomen. Radiology $1977 ; 125: 135-40$.

\title{
Sulphasalazine in rheumatoid arthritis
}

\author{
B MCCONKEY, R S AMOS, S DURHAM， P J G FORSTER, S HUBBALL, L WALSH
}

\section{Summary and conclusions}

Seventy-four patients with rheumatoid arthritis were treated with sulphasalazine. There was a significant improvement in clinical score, with substantial falls in serum C-reactive protein concentrations and erythrocyte sedimentation rate four weeks after starting the drug. Improvement was maintained in the 38 patients who remained on the drug for one year. The mean RoseWaaler titre did not change. There was little difference between the results in seropositive and seronegative patients. The commonest adverse effect was dyspepsia, but five patients developed a megaloblastic anaemia and one patient neutropenia; all made a complete recovery.

The results suggest that the drug has a diseasemodifying action not attributable to its "salicylate" content. The mode of action might be by an antibacterial effect on gut flora.

\section{Introduction}

The finding that dapsone is effective in rheumatoid arthritis $(\mathrm{RA})^{1}$ led us to consider related alternatives. We had studied dapsone partly because of its effect in leprosy and dermatitis herpetiformis; its mode of action in those diseases may be through its immunosuppressant properties. $^{2}$ Another drug used in dermatitis herpetiformis is sulphapyridine; it did not attract us as a contender but it is a constituent of salicyl-azosulphapyridine (sulphasalazine), a compound originally formulated for $\mathrm{RA}^{3}$ and latterly found to have immunosuppressant properties. $^{4}$

The early trials of sulphasalazine in rheumatoid arthritis produced conflicting results ${ }^{5}$; our recent pilot study ${ }^{7}$ encour-

Dudley Road Hospital, Dudley Road, Birmingham B18 7QH

B McCONKEY, DM, FRCP, consultant physician

R S AMOS, MB, MRCP, Sheldon clinical research fellow

(present address: Rheumatism Research Unit, School of Medicine, Leeds)

$S$ DURHAM, MB, MRCP, senior house officer

(present address: Brompton Hospital, Fulham Road, London)

$P$ J G FORSTER, $M B, M R C P$, research registrar

$S$ HUBBALL, BSC, AIMLS, technician

L WALSH, chief technician aged us to perform a larger investigation of the effects of sulphasalazine over period up to a year in 74 patients with rheumatoid arthritis.

\section{Patients and methods}

We studied 74 patients with definite or classical rheumatoid arthritis (according to the criteria of the American Rheumatism Association). Each patient had clinically active disease with a serum C-reactive protein concentration of over $20 \mathrm{mg} / \mathrm{l}$ or an erythrocyte sedimentation rate (ESR) of over $20 \mathrm{~mm}$ in the first hour.

Six patients stopped sulphasalazine within 28 days and their data are excluded from the results; they are accounted for under "adverse effects." The remaining 68 patients, 52 women and 16 men, had a mean age of 51.7 years (range 20-77 years) and a mean duration of rheumatoid arthritis of 8.1 years (range 3 months-33 years). Thirty-nine patients were seropositive with Rose-Waaler titres of $1 / 32$ or greater. All patients were taking a non-steroid anti-inflammatory drug, but no other drugs were used. Forty patients had previously been treated with disease modifying drugs. In only six cases was the interval between stopping these drugs and starting sulphasalazine less than six months.

After a preliminary assessment period of six weeks, enteric-coated sulphasalazine was started at an initial dose of $0.5 \mathrm{~g}$ daily, increasing by $0.5 \mathrm{~g}$ increments at weekly intervals to a usual maintenance dose of 2 g per day.

Subjective clinical state was recorded as clinical score. ${ }^{8}$ At the first visit each patient was allotted an arbitrary score of 100 . Subsequently, at every visit the patient was asked whether he felt better, worse, or the same compared with last time. The score of 100 was altered by +2 if better, -2 if worse. These cumulative scores were standardised to 100 at the start of treatment with sulphasalazine. Serum C-reactive protein was measured by radial immunodiffusion and ESR by the Westergren method.

Patients did not attend at exactly regular intervals, and time points ( \pm 14 days) with the largest number of results were chosen for data analysis. Student's $t$ test for paired variants was used to assess significance.

\section{Results}

During the six-week preliminary period of treatment with a nonsteroid anti-inflammatory drug there was slight subjective clinical deterioration and there were minor, but not significant, changes in mean serum C-reactive protein and ESR (see table).

At the start of treatment with sulphasalazine mean serum C- 